\title{
O PEN SAMENTO DIALÉTICO DE BENTO DE JESUS \\ CARAÇA E SUA CONCEPÇÃO DA EDUCAÇÃO MATEMÁTICA
}

\section{The dialectical thinking of $B$ ento de Jesus $C$ araça and his conception of mathematics education}

\author{
Cleide Farias de M edeiros \\ Alexandre M edeiros
}

\begin{abstract}
Resumo: Este texto enfoca a vida e a obra de Bento de Jesus $C$ araça, matemático e educador português da primeira metade do século $X X$ que muito influenciou a produção em Educação $M$ atemática em língua portuguesa. Tecendo alguns importantes fragmentos biográficos tentamos construir uma visão deste importante personagem na qual ele possa ser contemplado em toda a extensão do significado humanístico de sua vida e do impacto educacional e da atualidade de sua obra, assinalando o centenário do seu nascimento. Importa-nos tornar clara a perfeita sintonia existente entre as suas convicções socialistas e a sua prática como educador. Esta vinculação é apontada como sendo decorrente, principalmente, da sua interpretação dialética da história e da produção do conhecimento.
\end{abstract}

Unitermos: educação matemática; Bento de Jesus C araça; interpretação dialética da história; educação e socialismo; produção do conhecimento.

\begin{abstract}
This text focuses on the life and work of Bento de Jesus Caraça, Portuguese mathematician and educator, who lived during the first half of the XXth Century and much influenced the Mathematics Education field in countries whose spoken language is Portuguese. $M$ arking the centenary of his birth, some of his important biographic excerpts are interwoven and by doing this we attempt to construct a view of this important character. H e may be viewed through the humanistic meaning of his life as well as through the educational impact of his work which is still current. It is important for us to make dear the existing coherent relation between his socialist convictions and his practice as an educator. This relationship is shown to be a result mainly of his dialectical interpretation of history and the production of knowledge.
\end{abstract}

Keywords mathematics education; Bento de Jesus Caraça; dialectic interpretation of history; education and socialism; production of knowledge.

\section{Introdução}

O nome de Bento de Jesus C araça constitui um marco na produção em Educação $M$ atemática em língua portuguesa. Seu livro Conceitos fundamentais da matemática influenciou gerações de educadores e constitui-se ainda em um referencial obrigatório para todos aqueles que desejem explorar a dimensão humanística da criação matemática. As discussões conceituais, aliadas às incursões históricas e filosóficas, contidas naquela obra, inspiraram muitos educadores e continuam ainda a fazer escola. 0 ano de 2001 assinalou os cem anos do nascimento deste personagem que foi, entretanto, muito mais do que um grande professor da M atemática e autor de um livro consagrado.

${ }^{1} \mathrm{PhD}$ (Centre for Studies in Science and M athematics Education - U niversity of Leeds). M estre em Psicologia da Educação (Pontifícia U niversidade Católica de São Paulo). Professora do D epartamento de Educação da U niversidade Federal Rural de Pernambuco - email: cfmed@hotlink.com.br

${ }^{2} \mathrm{PhD}$ (Centre for Studies in Science and M athematics Education - U niversity of Leeds). M Sc.(FEU SP). Professor do D epartamento de Físca e M atemática da U niversidade Federal Rural de Pernambuco - email: med@hotlink.com.br 
Caraça foi, acima de tudo, um humanista preocupado com os destinos da humanidade e a construção de um novo mundo de paz e de esperança. Sua atuação política em defesa da justiça, liberdade e da igualdade dos homens é um autêntico testemunho de integridade. Sua visão da Educação, da Filosofia e da M atemática é um exemplo de modernidade que o coloca como um vulto ainda atual. Explorar, ainda que superficialmente, a sua vida e a sua obra é uma aventura recompensadora que nos eleva aos pontos mais altos da dimensão humana.

\section{Tecendo alguns fragmentos biográficos}

O s fragmentos biográficos tecidos a seguir são oriundos de várias fontes, principalmente dos relatos contidos na coletânea intitulada Bento de Jesus $C$ araça: conferências e outros escritos, editada originalmente em 1970. Ali encontramos os testemunhos de Ruy Luis G omes e de $M$ anuel $M$ endes, dois de seus mais distintos colegas. A maior parte dos fragmentos, entretanto, vem dos muitos depoimentos apaixonados dados por ex-colegas e ex-alunos e outros estudiosos da sua vida e da sua obra, muitos dos quais estão disponíveis na Internet. D entre eles, destacamos os dos seus camaradas Álvaro Cunhal (2001) - secretário do partido comunista português - e de Manuel Gusmão (2001), Antonio Abreu (1995) e Alberto Vilaça (1999). D estacamos, ainda, os relatos do historiador Antonio Borges Coelho (2001), do professor C arlos M anuel D obreira (2001), da médica Lina Seabra D inis (2001), da economista M aria M anoela Fisher (2001), dos economistas Sérgio Ribeiro (2001) e economista U Ipiano N ascimento (2001), de João Caraça (2001), de N atália Bebiano (2001a; 2001b), de Esteves Belo (2001), de Barata-M oura (2001), de Ludgero Pinto Basto (2001), de Armando M yre D ores (2001), de Lídia H omem de M elo (2001) e o da engenheira Guida Lami (2001), uma de suas mais distintas al unas e que fez os desenhos para o seu famoso Concei tos fundamentais da matemática. São muitos a recordar do grande vulto que foi Bento de esus Caraça. A importância das homenagens a ele conferidas em Portugal no ano de 2001 foi de tal envergadura que a Sessão Comemorativa do C entenário do $\mathrm{N}$ ascimento de Bento de Jesus Caraça, ocorrida no Instituto Superior de Economia e G estão - ISEG, em 18 de Abril de 2001, foi presidida pelo próprio Presidente da República de Portugal.

Bento de Jesus C araça nasceu no dia 18 de Abril de 1901, em Vila Viçosa, Portugal. De origem humilde, tendo seus pais sido trabalhadores rurais, cresceu em uma fazenda na qual seu pai era o feitor. Lá aprendeu a ler com os trabalhadores. Criança precoce, sua inteligência chamou a atenção da esposa do patrão do seu pai que se responsabilizou pela sua educação. Aos dez anos (1911) terminou o curso primário com distinção. Estudou, em seguida, no liceu de Santarém e no Pedro N unes, em Lisboa, onde concluiu sua educação secundária em 1918. N aquele mesmo ano entrou para o Instituto Superior do Comércio, que posteriormente mudaria sua denominação para Instituto Superior de Ciências Econômicas e Financeiras. Já em 1919, então no segundo ano como estudante no Instituto, foi nomeado 2 은 assistente - uma espécie de monitor - das disciplinas matemáticas. 0 ano de 1919 assinala, efetivamente, 0 início da brilhante carreira docente de Bento de Jesus Caraça, não apenas como professor de M atemática, mas também como grande divulgador das modernidades científicas para as massas trabal hadoras. Esse seu engaj amento nas questões sociais explicita-se com a sua participação ativa na fundação da U niversidade Popular Portuguesa, uma entidade ligada ao partido comunista que desempenhou um importante papel na cultura portuguesa na primeira metade do século XX e da qual Bento de Jesus veio a se tornar presidente a partir de 1928. A U niversidade Popular Portuguesa foi fundada em 1919 por um grupo de intelectuais e de trabalhadores, com o objetivo de difundir a instrução e a cultura no bairro em que foi criada e, logo, a sua ação se difundiu às classes trabalhadoras de Lisboa como um todo. H avia, 
além da sede, departamentos da Universidade Popular distribuídos no meio operário. D a sua primeira direção, que se designava Consel ho Administrativo, faziam parte, entre outros, 5 professores e 7 operários, 0 que marca desde logo 0 caráter daquela instituição. A idéia era organizar várias atividades culturais para os trabalhadores. A Engenheira Guida Lami, por exemplo, menciona um curso que lecionou, ainda quando estudante, cujo tema era a "Energia Atômica para O perários".

A Universidade Popular era um centro de difusão da cultura, onde ocorriam atividades das mais variadas: concertos, conferências, entrevistas, cursos, peças teatrais e cinema. Com a sede localizada em um velho edifício da Rua Luis D erouet, em cima da antiga Padaria do Povo, a Universidade Popular era de fato um centro de agitação cultural e prazer intelectual, além de servir de fermento para novas militâncias comunistas.

As conferências eram sintéticas e harmoniosas, versando sobre assuntos que pudessem interessar ao indivíduo na sua condição de homem moderno, qualquer que fosse a sua profissão ou posição na sociedade. As sessões de cinema ocorriam tanto na sede quanto nas sucursais da U niversidade. $\mathrm{H}$ avia, também, uma biblioteca que chegou a ter 10 mil volumes, além de bibliotecas móveis que circulavam nas sucursais estabelecidas nos meios operários. As leituras eram incentivadas tanto para os adultos, quanto mesmo para as crianças. Eram promovidas excursões, teatro, sessões musicais e sinfônicas populares. H avia, também, um laboratório de psicologia experimental assim como um Conselho pedagógico para orientação das leituras.

0 espírito da Universidade Popular fica patente em uma conferência proferida em 1931 por Bento de Jesus C araça. Ele fazia parte do Conselho Administrativo desde o início da Universidade e proferiu a referida conferência intitulada: As U niversi dades Popularese a Cultura, já como presidente da entidade. $\mathrm{N}$ ela, $\mathrm{C}$ araça levantou a questão central que inspirara a criação da Universidade Popular: Encarando agora as sociedades organizadas, tal como atualmente $s$ encontram, pergunta-se - quem deve ser o detentor da cultura?, a massa geral da humanidade, ou uma parte dela? (Apud D ores, 2001, p. 3). Sua própria resposta era inequívoca:

A pergunta feita deve responder-se condenando a detenção da cultura como monopólio de uma elite... D eve portanto promover-sea cultura de todos eisso é posśvel porque ela não é inacesśvel à massa; 0 ser humano é indefinidamente aperfeiçoável e a cultura é exatamente a condição indispensável desse aperfeiçoamento progressivo e constante (Apud Dores, 2001, p. 3).

0 ano de fundação da Universidade Popular, 1919, foi, por vários motivos, um marco na vida de Bento de Jesus $\mathrm{C}$ araça. $\mathrm{N}$ aquele ano, além de iniciar sua carreira docente $\mathrm{e}$ sua participação na U niversidade Popular, al iada à sua intensa militância política de esquerda, foi, também, acometido de uma doença da qual resultou o mal que mais tarde o levaria à morte. Por causa desta doença, de cujos efeitos futuros ele nem ao menos suspeitava, ficou-Ihe a impressão de que os seus pulmões eram fracos. Por isso, todos os anos Bento Caraça ia passar um mês na Serra da Estrela, entrando em contato direto com a natureza e andando dias seguidos pelas alturas da Serra.

Bento concluiu os seus estudos em Ciências Econômicas, com distinç̧ão, em 1923. No ano seguinte foi nomeado 1 - assistente; em 1927 professor extraordinário e em dezembro de 1929 professor catedrático das M atemáticas Superiores (Álgebra Superior, Princípios de Análise Infinitesimal e G eometria Analítica).

$M$ atemático de talento, além de excelente professor, sabia incentivar seus alunos a criarem gosto pelo estudo através da construção de um relacionamento amistoso duradouro, 
mas bastante exigente. Publicou diversas obras e artigos sobre $M$ atemática, dentre as quais se destacam: Interpolação e integração numérica (1930-32), Li ç̃oes de álgebra e análise, em 2 volumes (1935-1940) e Cálculo vectorial (1937). Em 1938 participou com outros colegas professores (M ira Fernandes e Beirão da Veiga) da fundação do Centro de Estudos de M atemáticas A plicadas à Economia, do qual foi diretor até outubro de 1946, ano da sua extinção por decisão governamental. Foi, também, fundador da Gazeta da M atemática, em 1940, juntamente com os professores António M onteiro, Hugo Ribeiro, José da Silva Paulo e M anuel Zaluar. Em 1944, Bento Caraça foi eleito presidente da Sociedade Portuguesa de M atemática para 0 biênio 1943-44.

H umanista autêntico, com sólida formação marxista, combatia o monopólio cultural das classes dominantes destacando a criatividade e pujança da cultura popular assim como a importância da democratização dos saberes mais eruditos. Apontava o valor e o papel do indivíduo na sociedade, inserindo as atividades individuais nas realizações coletivas. Sereno e tolerante nas controvérsias, apesar de manter-se firme em suas convicções filosóficas, refletia constantemente e incentivava os outros a refletirem também sobre as diversas opiniões emitidas nas discussões. Sempre confiante no futuro da humanidade, acreditava e amava a juventude, convivendo intensamente com os mais jovens que com ele conversavam e passeavam alegremente. Sua contribuição cultural literária expressou-se na colaboração com diversos periódicos, tais como: a Revista do Instituto Superior de Comércio, a Revista da Economia, Técnica, Seara N ova, Vértice, o quinzenário 0 Globo, que fundou juntamente com Rodrigues M igueis; e nos semanários 0 Diabo e A Liberdade.

D entre os marcos culturais deixados por Bento de Jesus C araça, destaca-se a criação, em 1941, da coleção intitulada Biblioteca Cosmos da qual foi o único diretor. Autêntica enciclopédia do saber, pioneira mesmo na Europa, a Biblioteca Cosmos publicou 114 títulos, com uma tiragem total de 793.500 exemplares. Bento Caraça idealizou a coleção de livros com 0 intuito de que eles abarcassem o conjunto de conhecimentos então considerados importantes para a cultura de um indivíduo, uma cultura que ele chamava de integral. Os títulos eram muito variados, mas carregavam todos a preocupação de trazer uma nova visão de mundo que se chocasse contra a paralisia imposta pelo tradicionalismo da sociedade portuguesa.

Livros como os de Flausino Torres, Civilizações primitivas e Religiões primitivas, ou o texto sobre Psicanálise de Joaquim Seabra Dinis, por exemplo, tinham um papel questionador e exerceram, aos seus modos, um grande impacto sobre a juventude e sobre os trabal hadores portugueses. Foi, também, através da Biblioteca C osmos que Bento de J esus $C$ araça veio a publicar o seu influente livro Concei tos fundamentais da matemática. Esse livro revolucionou a abordagem da $M$ atemática através de um tratamento interdisciplinar cal cado em um enfoque histórico e dialético deste majestoso empreendimento humano.

As convicções filosóficas de Bento de J esus C araça corporificaram-se não apenas em sua postura enquanto humanista e educador, mas igualmente na sua militância política. M ilitante desde a juventude, Bento intensificou sua atividade política com a subida do fascismo ao poder, quer a nível clandestino com a militância comunista, quer com a sua aberta participação na Liga Portuguesa contra a Guerra e o Fascismo e no Socorro Vermelho Internacional. M ais tarde participaria, também, em 1943, da fundação do M ovimento Unificado $\mathrm{N}$ acional Anti Fascista, M UN AF, e em 1945 do M ovimento da U nidade D emocrática, M U D.

Perseguido constantemente pela ditadura fascista, jamais abdicou, porém, dos seus ideais de liberdade e igualdade dos homens. Apesar da brandura do seu caráter, reagiu sempre com extrema firmeza a todas as pressões recebidas que tentavam coagir a sua atuação política. Resistente antifascista, paladino da liberdade e da democracia, apontava como horizonte 
mais amplo de luta a necessidade de profundas transformações sociais, da construção de uma sociedade sem exploradores nem explorados, de uma autêntica sociedade socialista. Acabou por ser preso pela PIDE, a polícia política da ditadura fascista de Portugal, sendo, posteriormente, demitido do seu cargo de professor catedrático do Instituto Superior de Ciências Econômicas e Financeiras em 0 utubro de 1946. M orreu em Lisboa, em 25 de Junho de 1948, com ape nas 47 anos de idade, vítima de reumatismo articular agudo, doença irreversível na época.

0 funeral de Bento de Jesus C araça foi carregado de emoção, tendo sido seguido por milhares de pessoas, tal a sua popularidade e o respeito que lhe era dedicado pelo povo português. Converteu-se, assim, em uma enorme expressão de pesar do sentimento popular pela morte de um ente tão querido. Seu funeral foi, nas palavras de Álvaro Cunhal, seu companheiro de partido, uma homenagem sentida do povo português a um dos maiores intelectuais portugueses de todos os tempos que, apesar do enorme prestígio intelectual alcançado, jamais esqueceu a sua origem de classe nem nunca se desvencilhou de sua humildade.

\section{0 pensamento humanista de Bento de Jesus $C$ araça}

D e todas as características do pensamento e da atuação de Bento de Jesus C araça, a sua dimensão humanística sobressai-se por ser nela que radicam todas as outras vertentes da vida e da obra deste grande personagem e pensador. Seu humanismo de matiz socialista tem como característica marcante 0 tom das ações coletivas: ciência, filosofia, arte, religiões, têm uma raiz comum - a actividade social dos homens (Caraça, 1978, p. 187).

Revolucionário, por excelência, e muito perceptivo quanto às transformações ocorridas, Bento Caraça afirmava que:

0 poder revolucionário de uma idéa medese pelo grau em que ela interpreta as aspiraçoes gerais, dadas as circunstâncias do momento em que atua. Assim, uma idéia ou teoria que, em dada época, é revolucionária, pode, noutra em que as circunstâncias sejam diferentes, ter perdido por completo esse carácter (C araça, 1978, p. 39).

Combatia a inconseqüência das atitudes individualistas nas ações humanas, no seio da sociedade apegando-se à dialética que determinava a mudança das coisas. Em suas próprias palavras: 0 grande erro dos individual istas de hoje é o de conservarem-se agarrados à letra das fórmulas, sem notarem que os termos têm agora um sentido novo que Ihe é emprestado pela diferença fundamental das circunstâncias (Caraça, 1978, p. 43). Assinalando, ainda neste mesmo sentido, que as ações humanas precisavam ser interpretadas dentro do contexto de influências em que eram produzidas, afirmava que Toda a vida humana é uma lenta criação, fruto de interacções do indivíduo e do seu meio, do seu contexto (C araça, 1978, p. 290).

Para ele, o desafio maior residia na necessidade de organização das ações coletivas: a grande tarefa que está posta, com toda a sua simplicidade crua, à nossa geração édespertar a alma colectiva das massas (Caraça, 1978, p. 48).

Via nas ações coletivas o verdadeiro motor das transformações sociais e a única forma conseqüente de deter as injustiças sociais e de caminhar em direção da construção de uma sociedade mais fraterna:

construímos cinemas sumptuosos etemosfalta de casa dehabitação. Gastamos em navios de guerra o dinheiro necessário para as escolas. 0 s ricos podem gastar num só jantar 0 salário semanal de um operário, enquanto o operário não pode enviar à escola os fil hos insuficientemente alimentados (C araça, 1978, p. 45). 
Referindo-se à tarefa urgente de cada ser humano emitir um juízo de valor sobre o tempo em que ele vive, Caraça alerta sobre o fato de que:

o que o mundo for amanhã é 0 efforço de todos nós que o determinará. Há que resolver os problemas que etão postos à nossa geração e essa resol ução não a poderemos fazer sem que, por um prévio efforço do pensamento, procuremos saber, por uma análise fria e raciocinada, quais são esses problemas, quais as soluções que importa dar-Ihes - saber donde vimos, onde etamos, para onde vamos (C araça, 1978, p. 33).

Percebia a sofisticação da produção da riqueza, trazida com o avanço do capitalismo. C ontemplava as máquinas substituindo o trabal ho humano nas fábricas, mas não tirava daí qualquer sensação de angústia ou de desespero. Antes pelo contrário, refletia criticamente sobre o papel da tecnologia:

A existência da máquina na vida de hoje é um facto contra o qual não há que fantasiar nem lamuriar. Ela veio a introduzir-se lentamente, ganhando pouco a pouco novos campos e já agora não é concebível o desenvolvimento normal da vida dos povos sem ela; mais ela está destinada a tomar nesse desenvolvimento uma parte cada vez maior [...] O s males não estão na máquina mas na desigualdade de distribuição dos benefícios que ela produz. 0 mal não etá em que se reduza de 100 a 5 o número de horas necessário para a fabricação de dado produto, mas sim em que o benefício correspondente seja reservado a uma minoria, escravizando a essa má distribuição a maioria. Q uer dizer, o problema fundamental é, não um problema de técnica, mas um proble ma de moral social. E não é aos técnicos que se pode entregar a sua resolução. É aos homens (C araça, 1978, p. 54).

E para que esses mesmos homens pudessem atuar, realmente, como agentes da justiça, da paz e da liberdade, precisariam ser sábios, precisariam para isso adquirir aquilo que ele chamava de uma "cultura integral" voltada para o desenvolvimento do espírito de solidariedade:

Eduquemos e cultivemos a consciência humana, acordemo-la quando estiver adormecida, demos a cada um a consciência completa de todos os seus direitos e de todos os seus deveres, da sua dignidade, da sua liberdade [...] o reconhecimento a todos do direi to ao completo e amplo desenvolvimento das suas capaci dades intel ectuais, artísticas e materiais (Caraça, 1978, p. 8).

M as em que consistia essa cultura integral do indivíduo, vislumbrada por Bento C araça? Consistia na idéia de ser ela o caminho da liberdade e da cidadania. afirmando que:

M as, afinal, o que significa ser um homem culto? Caraça responde a esta pergunta

H omem culto é aquele que: 1. tem consciência da sua posição no cosmos e, em particular, na sociedade a que pertence; 2 . tem consciência da dignidade que é inerente à existência como ser humano; 3. faz do aperfé çoamento do seu ser interior o fim último da vida. Ser culto não implica ser sábio. H á sábi os que não são homens cul tos e homens cultos que não são sábios (C araça, 1978, p. 51). 
Para C araça, a aquisição da 'cultura integral' necessária significa:

U ma elevação constante, servida por um florescimento do que há de melhor no homem e por um desenvolvimento sempre crescente de todas as suas qualidades potenciais, consi deradas do quádruplo ponto de vista físico, intelectual, moral e artístico; significa, numa palavra, a conquista da liberdade.

E para atingir esse cume elevado, acessivel a todo o homem, como homem, e não ape nas a uma classe ou grupo, não há sacrifício que não mereça fazer-se, não há canseira que deva evitar-se. A pureza que se respira no alto compensa bem da fadiga da ladeira (1978, p. 51).

Esta visão de mundo enfatiza a sua posição enquanto um educador. Ela, entretanto, tem um desdobramento político evidente, pois a sabedoria para $\mathrm{C}$ araça, como fruto da cultura integral, traz conseqüências dramáticas. Essa cultura deveria propiciar ao homem, não ape nas 0 al argamento dos seus horizontes de compreensão da realidade, mas também, 0 seu dese jo de intervir nessa mesma realidade. Em um tal cenário, não haveria lugar para desânimos, tais os desafios que a situação oferecia. Bento de Jesus $C$ araça alerta-nos, em conseqüência, contra o perigo do derrotismo. Ao justificar, por exemplo, a criação da Biblioteca Cosmos, ele escreveu: H á em suma que dar ao homem uma visão otimista de si próprio; o homem desiludido e pessimista é um ser inerte suje to a todas as renúncias, a todas as derrotas - e derrotas, só existem aquelas que se aceitam (apud Sucena, 2001, p. 1).

Para aqueles que consideram as suas posições utópicas, ilusórias, ele responde com veemência em sua célebre conferência A Cultura Integral do H omem:

Asilusões nunca são perdidas. Elas significam o que há de melhor na vida dos homense dos povos. Perdidos são os cépticos que escondem sob uma ironia fácil a sua impotência para compreender e agi r; perdidos são aqueles períodos da história em que os melhores, gastos e cansados se retiram da luta, sem enxergarem no horizonte nada a que se entre guem, caída uma sombra uniforme sobre o pântano estéril da vida sem formas (Caraça, 1978, pp. 31-32).

Sua concepção dialética da real idade expressa-se na sua convicção de que: A evolução e o tranformar-se permanente de todas as coisas é lè da vida, quer isso seja ou não da nossa simpatia, e todas as pessoas que o ignoram ou esquecem exão sujeitas a encontrar-se na vida em situações deploráveis... (C araça, 1943, In: Vilaça, 1999, p. 243).

Esse seu humanismo não se esgota, entretanto, em uma atuação teórica. Caraça desenvolve ações concretas em prol dos operários portugueses, exigindo a melhoria de sua condição de vida, através da luta pelos seus direitos sociais. O s trabal hadores, por exemplo, que àquela altura erguiam, com a força dos seus braços, a Barragem da Lagoa Comprida, com a falta de maquinaria adequada, comparativamente aos dias atuais, sentiram nas suas palavras a defesa dos interesses do operariado. C araça procura demonstrar aos trabal hadores as vantagens que para todos poderia resultar da fundação de um sindicato, explicando-Ihe, ainda, em grandes linhas, o seu funcionamento e para que serviria fundar uma cooperativa de socorros mútuos em caso de greve.

Após ter entrado na U niversidade, a sua rica personalidade, trabal hada e desenvolvida por constantes, metódicas e selecionadas leituras e, simultaneamente, pelo trabalho escolar 
e pelas suas intervenções como tribuno, como doutrinário e como orientador, nas associações, nas academias, e nas sociedades e publicações culturais dessa época, tornou-o uma espécie de ídolo da mocidade estudantil e universitária e em um alvo da ditadura fascista em Portugal.

Como professor catedrático de $M$ atemática, sempre ligado às suas origens sociais, C araça desempenhou um papel ímpar na formação de quadros para o partido comunista, no dizer do próprio Álvaro Cunhal. Jogou, também, um papel preponderante na criação nos jovens do gosto pela Ciência, pela cultura e pelas artes e na democratização dos conhecimentos, de que é testemunho a sua inspirada direção da edição de numerosos e valiosos estudos na coleção Cosmos.

A sua luta política desenvolveu-se, particularmente, no mais amplo movimento unitário clandestino contra a ditadura ( o M U N AF, o C onselho N acional e o M UD), na luta contra a ofensiva hitlerista e pela paz, na organização dos Amigos da U nião Soviética e na val orização da construção da sociedade socialista. C omo lembra C unhal, a ditadura não Ihe perdoou esta múltipla atividade. Foi perseguido, demitido do professorado e preso nos cárceres da PIDE.

\section{Matemática \\ Uma visão dialética do desenvolvimento histórico da Ciência e da}

A postura filosófica de Bento de Jesus Caraça diante da produção do conhecimento deriva da mesma matriz em que radica o seu humanismo de inspiração socialista: na sua concepção dialética da história e da natureza. É essa consciência de desenvolvimento histórico não linear que o faz colocar em perspectiva crítica a forma como a Ciência e a M atemática estabeleceram-se enquanto criações humanas. Em seus pensamentos sobre a Ciência e sobre a $M$ atemática, manifesta a mesma convicção presente na sua visão socialista sobre a importância do trabalho coletivo. U sa esse importante conceito de trabalho coletivo para compreender o próprio desenvolvimento histórico da Ciência. Chega mesmo a ser irônico ao referir-seà história concebida apenas como um produto de contribuições individuais de grandes gênios. N este ponto, seu pensamento está em sintonia com o grande poema de Bertold Brecht: Perguntas de um operário que lê:

Quem construiu a Tebas das sete portas?

N os livros constam os nomes dos reis.

Os reis arrastaram os blocos de pedra?

E a Babilônia tantas vezes destruída

Quem a ergueu outras tantas?

Em que casas de Lima radiante de ouro

M oravam os construtores?

Para onde foram os pedreiros

$\mathrm{N}$ a noite em que ficou pronta a M uralha da China?

A grande Roma etá cheia de arcos de triunfo.

Quem os levantou?

Sobre quem triunfaram os césares?

A decantada Bizâncio só tinha palácios

Para seus habitantes?

M esmo na legendária Atlântida,

$\mathrm{Na}$ noite em que o mar a engoliu,

Os que se afogavam gritavam pelos seus escravos. 
0 jovem Alexandre conquistou a India.

Ele sozinho?

César bateu os gauleses.

$\mathrm{N}$ ão tinha pelo menos um cozinheiro consigo?

Felipe de Espanha chorou quando sua Armada naufragou.

Ninguém mais chorou?

Frederico II venceu a Guerra dos Sete Anos.

Quem venceu além dele?

U ma vitória em cada página.

Quem cozinhava os banquetes da vitória?

U m grande homem a cada dez anos.

Quem pagava suas despesas?

Tantos relatos.

Tantas perguntas (Brecht, Apud Alencar, 1985, p. V).

No mesmo tom do poema de Brecht, Bento C araça afirma enfaticamente:

Há quem considere a obra dos grandes homens como produto exclusivo das suas qualidades pessoais, independentemente de quaisquer influências externas, e quem vá até ao ponto de afirmar que o progresso humano, mesmo naquilo que ele tem de mais palpável, o conhecimento da natureza, se faz ao acaso do aparecimento de homens geniais. Felizes pessoas essas que com pouco se contentam, e para quem uma universal bruxaria na distribui ção dos gênios pelo espaço e pelo tempo chega para explicar a marcha da civilização (C araça, 1978, p. 155).

Assumindo uma postura epistemológica bem moderna, compatível com as de outros grandes pensadores do seu tempo, C araça investe contra o determinismo na Ciência, apoiando-se nas recentes conquistas da Física Q uântica:

A filosofia da ciência, no seu efforço de tentar uma compreensão geral do U niverso, correu durante muito tempo atrás do fantasma do objecto-em-si e sobre ele construiu uma noção ambi ci osa de determi ni smo. M as quando o observador se aproximou mais do fantasma, e procurou ver como conseguiria determinar com precisão a posição e a velocidade duma partícula material num dado instante, apercebeu-se de que ele, homem-observador, formava, juntamente com a partícula observada e os instrumentos de observação, um grupo solidário, com o seu condicionamento próprio, as suas acções e reacções próprias entre observado, instrumento e observador.

E o fantasma partícula-em-si desvaneceu-se, e com ele, o outro fantasma de segunda ordem - o determinismo mecanicista (C araça, 1978, p. 186).

Tendo sempre a relação dialética entre a teoria e prática em sua mente, C araça rejeita as posturas idealistas que creditam à $M$ atemática uma origem exclusivamente racional. Este seu ponto de vista sobre a produção dialética do conhecimento matemático irá influenciar decisivamente a sua postura como educador ao tentar sempre traçar um arco histórico da produção das idéias matemáticas que abarque a teoria e a prática. D este modo, rejeita, com vigor, a concepção da M atemática como uma Ciência desligada da realidade cotidiana, tomando-a na complexidade do seu processo histórico construtivo para poder captar o seu significado mais profundo: 
$N$ ão é raro encontrar entre um grande número de pessoas, mesmo daquelas que pela sua cultura geral e habilitação profissional, fazem parte daquilo a que convenciona chamarse a 'elité de um país, esta opinião acerca da M atemática - que se trata de uma ciência abstracta, de um campo fechado onde só poucos entram, campo dominado por preocupações inteiramente à margem dos problemas e das preocupações quotidianas dos homens. Tal opinião, nem por ser muito espalhada é mais conforme com a realidade dos factos. É claro que existem na matemática, como aliás em qualquer outro ramo da Ciência, 'problemas próprios', nascidos exclusivamente dela e só acessíve's aos seus especialistas. $M$ as não é menos verdade que, considerada a $M$ atemática como um todo em evolução, Ihe desaparece inteiramente o caráter de domínio fechado e bastando-se a si próprio e, pelo contrário, se descortinam bem claramente as ligações àquele conjunto comum de preocupações, problemas e realizações que determinam, em última análise, a marcha do pensamento e da civilização (C araça, 1978, p. 293).

Este tema da relação histórica entre a teoria ea prática na produção do conhecimento matemático parece dos mais preciosos para Bento Caraça. Ele o retoma, ainda com maior vigor e brilhantismo das palavras, na Introdução do seu famoso livro Conceitos fundamentais da M atemática:

A M atemática é geralmente considerada como uma ciência à parte, desigada da realidade, vivendo na penumbra do gabinete, um gabinete fechado, on de não entram os ruídos do mundo exterior, nem o sol nem os clamores dos homens. I sto, só em parte é verdadeiro. Sem dúvida, a M atemática possui problemas próprios, que não têm ligação imediata com os outros problemas da vida social. M as não há dúvida também de que os seus fundamentos mergulham tanto como os de outro qualquer ramo da Ciência, na vida real; uns e outros entroncam na mesma madre (C araça, 1975, p. XIV).

0 mesmo tema reaparece na sua observação da crescente ligação da $M$ atemática com a realidade trazida pela vida moderna: D e todos os lados assi stimos a uma invasão crescente da vida moderna pela M atemática, a uma matematização das ciências que dia a dia se tornam mais imprescindíveis aos homens (C araça, 1978, p. 295).

D esdenha da visão estática da Ciência fornecida pelos livros didáticos, antecipando posturas críticas que apenas viriam a surgir muito depois de sua morte, com a obra marcante de Thomas Kunh, A estrutura das revoluções científicas, já nos anos sessenta. Essa sua postura crítica em relação aos textos didáticos, antecipa, igualmente, um campo atual de estudos na Educação M atemática. C araça, calcado na sua concepção dialética da história, argumenta com uma elegância na colocação das palavras poucas vezes rivalizada na Educação Científica e $M$ atemática contemporâneas. Ele afirma, textualmente, que:

A Ciência pode ser encarada sob dois aspectos diferentes. 0 u se ol ha para ela tal como vem exposta nos livros de ensino, como coisa criada, e o aspecto é o de um todo harmoni oso, onde os capítulos se encadeiam em ordem, sem contradições. 0 u se procura acompanhá-la no seu desenvol vimento progressivo, assi stir à maneira como foi sendo elaborada, e 0 aspecto é totalmente diferente - descobrem-se hesitações, dúvidas, contradiç̧ões, que só um longo trabalho de reflexão e apuramento consegue eliminar, para que surjam outras hesitações, outras dúvidas, outras contradições. D escobrese ainda qualquer coi sa mais importante e mais interessante: - no primeiro aspecto, a Ciência parece bastar-se a 
si própria, a formação dos conceitos e das teorias parece obedecer só a necessidades inte riores; no segundo, pelo contrário, vêse toda a influência que o ambiente da vida social exerce sobre a criação da Ciência.

A Ciência, encarada assim, aparece-nos como um organismo vivo, impregnado de condição humana, com as suas forças e as suas fraquezas e subordinado às grandes necessidades do homem na sua luta pelo entendimento e pela libertação; aparecenos, enfim, como um grande capítulo da vida humana social (Caraça, 1975, p. XIII).

Na sua reflexão enquanto um educador matemático, C araça não se contenta em tecer críticas apenas genéricas. Ele exemplifica os seus pontos de vista epistemológicos sobre a $M$ atemática, trabalhando a ligação da mesma com a realidade, no caso específico da formação do conceito de número natural. Sempre em tom enfático, uma característica marcante do seu estilo literário, afirma:

A idéa de número natural não é um produto puro do pensamento, independentemente da experiência; os homens não adquiriram primeiro os números naturais para depois contarem; pelo contrário, os números naturais foram-se formando lentamente pela prática diária de contagens. A imagem do homem, criando de uma maneira completa a idéia de número, para depois a aplicar à prática da contagem é cômoda, mas falsa (Caraça, 1975, p. 4).

\section{E continua, mais à frente, para acrescentar que:}

Para o homem civilizado de hoje o número natural é um ser puramente aritmético, des ligado das coisas reais e independente delas - é uma pura conquista do seu pensamento. Com essa atitude, o homem de hoje, esquecido da origem humilde histórica do número, e elevando-se (ou julgando elevar-se) acima da realidade imediata, concentrase nas suas possibilidades de pensamento e procura tirar delas o maior rendimento (Caraça, 1975, p. 10).

É deste tipo de enfoque epistemológico, no seio do qual se fundem suas convicções dialéticas da história com suas reflexões sobre a produção do conhecimento matemático, na tensão entre a teoria e a prática, que nascem suas convicções de educador matemático. Ele, entretanto, na condução de sua prática educativa, vai agregar a esses elementos filosóficos a sua atitude humanista de respeito, solidariedade e amor pelos seus semel hantes, construindo, desse modo, uma ação pedagógica que conquistará os seus muitos estudantes, convertendo-os de alunos em seus verdadeiros discípulos. Para além das suas belas e profundas reflexões filosóficas, que por si mesmas já bastariam para influenciarem os horizontes da Educação M atemática que se segue, ergue-se, acima de tudo, o exemplo de sua coerência com os princípios humanistas abraçados na condução de sua prática pedagógica.

\section{Um educador que transcende a sua época}

Estudar Bento de Jesus Caraça como educador é observar um exemplo de coerência. Suas idéias sobre a Educação e a Escola mostram-se não apenas em sintonia com a sua visão dialética, já acima comentada, mas, fundamentalmente, com a sua própria prática educacional. Boa parte de suas concepções educacionais mostram-se não apenas atuais como, ainda, necessárias. 
Caraça mostra-se um educador engajado, desacreditando de uma Escola neutra. Em sua visão, parece implícito o posicionamento de que todo trabal ho educacional incorpora uma visão de homem e de sociedade a ser mantida ou construída. Assim, ele torna explícita a sua crença na necessidade da abolição de privilégios e a sua defesa de uma igual dade de oportunidades para todos os indivíduos na aquisição do conhecimento erudito. Atento ao dito marxista de que a cada um, de acordo com as suas necessidades e de cada um, de acordo com as suas capacidades, demonstra uma percepção das diferenças entre as capacidades humanas, acreditando, porém, na possibilidade de auto-superação dos indivíduos. Afirma, com uma certa ironia:

A famosa neutralidade da escola, onde existe, ou existiu? $\mathrm{N}$ ão neste mundo, queme cons te. Pelo contrário, passando uma vista de ol hos pela história da pedagogia só encontraremos uma escola refletindo diretamente, na sua extensão e no seu conteúdo, a estruturação social do lugar a que se reportar.

A concepção que orienta a Escola Ú nica é a da abolição de privilégios perante a cultura - privilégios de sexo, privilégios de dinheiro, privilégios de crenças. A natureza humana éuma e todo o ser humano é, por conseqüência, portador dosmesmos direitos, a todos devem, portanto, ser proporcionada a completa aquisição dos conhecimentos que thes permitam viver dignamente a vida, conforme as suas capacidades - uma só condição, uma só dignidade, uma só escola (C araça, 1978, p. 105).

Em uma primeira análise, este pensamento de Caraça poderia equivocadamente lembrar uma concepção da Escola como um Aparelho Ideológico de Estado aproximando-o, portanto, de uma visão althusseriana (Althusser, 1980). Entretanto, a sua própria prática de vida demonstra ter ele uma concepção mais dialética da instituição Escola, como um espaço de contradições e de luta, no qual, a liás, tratou sempre de inserir-se combativamente. Ele percebe, como Gramsci, a possibilidade de atuar nas 'brechas' da sociedade civil veiculando contra-ideologias (Gramsci, 1982).

0 seu próprio caderno de anotações das suas aulas demonstra como Caraça fazia, por exemplo, uso da M atemática para explicar aos seus alunos detalhes da economia e da exploração capitalista. Em seus apontamentos manuscritos, encontramos definições e fórmulas para cálculo de preço, salário, mais-valia, taxa de exploração, taxas de lucro, etc. As anotações exprimem aspectos da tradução matemática das contradições do capitalismo. Ele usa a sua Matemática para expor aos seus estudantes, assim como aos trabalhadores na Universidade Popular, noções de preço natural e preço acidental. Isso Ihe permite conceituar o salário dos trabalhadores como um preço acidental da força de trabalho, uma quantidade de moeda trocada por uma mercadoria. São idéias essenciais, em sua visão marxista, para que o operário e o estudante possam compreender os conceitos-chave de mais-valia teórica e prática. Ele estabelece a diferença matemática entre os valores de troca dos produtos e da força de trabalho, na relação capitalista, como maisvalia teórica: $m=V-v$. D ifere a maisvalia prática da teórica, mostrando que a prática fundamenta-se entre os preços dos produtos e dos trabaIhos envolvidos: $m^{\prime}=V^{\prime}-V^{\prime}$. M ostra que se: $V^{\prime}=V+\varepsilon$ e $V^{\prime}=v-\delta$, então: segue com os raciocínios matemáticos até chegar ao estabelecimento da taxa de exploração. São noções rudimentares de economia, em uma visão marxista, que precisam de uma fundamentação matemática para serem compreendidas. E esse conhecimento, $C$ araça tenta passar aos seus alunos e aos operários, no Instituto e na U niversidade Popular. 0 seu caderno de aulas ilustra o conteúdo mencionado, conforme figura constante no site da Fundação M ario Soares (2001). 
Caraça defende o conceito de uma Escola U nica, que seja um fermento da igualdade entre os seres humanos, mas não tem uma visão cândida. Ele percebe que 0 bom funcionamento da instituição não depende apenas do seu aparel hamento material, depende também da responsabilidade dos seus professores. Ele explicita, entretanto, que o exercício dessa responsabilidade carrega a necessidade de uma formação cultural humanística e de uma situação econômica condigna por parte desses professores. E no seio dessa formação cultural, desponta, para ele, o conhecimento científico envolvido em sua formação histórica e social, como um elemento fundamental à sobrevivência e à busca da felicidade do ser humano.

0 tema ainda hoje atual e preocupante da formação dos professores foi apontado por C araça como uma questão ligada diretamente com o plano de estudos da "Escola Ú nica":

Este problema é da mais alta importância como facilmente se reconhece, pois o corpo de professores constitui a medula deste organismo, e do seu estado depende, portanto, a vida e saúde dele [...] 0 nível cultural dum povo depende, não apenas do número e apetre chamento das suas escolas, como também, e essencialmente, do grau de responsabilidade profissional do seu professorado primário. O ra, essa responsabilidade, só pode, de facto, ser tomada, quando o professor tiver uma formação cultural e gozar duma situação econômica tais, que a sua independência mental e a sua liberdade estejam inteiramente garantidas. $\mathrm{N}$ ão é esse, evidentemente, o caso com professores mal pagos, deficientemente formados, sobrecarregados de trabal ho e sem meios de desenvol vimento cultural na sua esmagadora maioria (C araça, 1978, pp. 113-114).

Caraça aborda, também, sem preconceitos, a questão polêmica da especialização. Ele combate a ingenuidade de rejeitar a especialização em troca de um enciclopedismo estéril, mas ressalta que a especialização só faz sentido se embebida em uma sólida formação humanística. Por que este ataque à especialização?

$\mathrm{N}$ ão é ela absolutamente necessária e imposta pelo progresso da ciência e da técnica? $0 \mathrm{u}$ temos que enfileirar junto daqueles ingênuos que vêem num retorno à vida simplesa salvação da civilização? Se se abandonar a formação especializada dos profi ssionais não se cai num enciclopedismo superficial que afinal não é nada? /.../ N ão se trata nada disso. Se amanhã a ciência tivesse de ser abandonada seria, não para passar a um estado melhor de civilização, mas para cair, por muitos séculos, num estado informe de barbárie. Do que se trata é de uma mudança de qualidade, isto é, de relações da ciência, da técnica, da máquina, para com o homem, da sua subordinação aos interesses superiores da sociedade. U ma coisa é 0 enciclopedi smo barato e estéril e outra é a formação humanista dos profissionais (C araça, 1978, p. 287).

Acima de tudo, Caraça mostra-se na prática, coerente com as teorias que adota em sua vida. Ele enquanto pedagogo é um homem que sempre interroga a si mesmo e afirma, peremptoriamente: se não receio o erro, é só porque estou sempre pronto a corrigi-lo (Caraça, 1978, p. 35). Seu amor aos seus alunos, à juventude, é uma autêntica profissão de fé: Q uero afirmar aqui a minha inteira solidariedade com estes moços que pretendem compreender e viver o seu tempo e trazer-Ihes, do mesmo passo, a minha modesta contribuição para o seu labor que será fecundo, na medida da força e poder de sinceridade que puserem... (C araça, 1978, p. 33). 
O s testemunhos de muitos de seus ex-al unos sobre sua conduta em sala de aula não deixam margem de dúvida quanto à coerência de suas atitudes e convicções. A Engenheira Guida Lami (2001), uma de suas alunas mais distintas, lembra com saudade do carinho com que le tra tava os estudantes, sempre dedicando-Ihes uma palavra de incentivo: Ah, não gosta de M atemática, então vai passar a gostar. Ela recorda, também, que ele, através de métodos muito simples, ligados à experimentação, começou a introduzi-la na M atemática. Em diversas universidades foram instituídos clubes de M atemática em grande parte inspirados pelo professor Bento Caraça, mas que depois acabaram por ser fechados. Caraça é descrito por seus discípulos como um extraordinário pedagogo, daí o grande impacto das suas lições sobre os al unos. Tanto Guida Lami quanto outra de suas ex-alunas, M aria M anuela Fisher (2001), testemunham que ele era um professor extremamente bom do ponto de vista pedagógico, bom conhecedor da M atemática, grande comunicador, mas ao mesmo tempo muito rigoroso. As aulas de M atemática quer pela atração quer pela novidade e pela beleza com que ele as abordava, eram a própria dialética. E que lições! D e uma clareza de exposição e de uma afabilidade e simpatias pessoais, que 0 aluno se sentia cativado e atraído, não só pela matéria, como pela própria personalidade do professor. D ava aula olhando atentamente para os rostos dos seus alunos. Por vezes parava e parecia ler os pensamentos, dirigindo-se a al guém mais calado e perguntava: $N$ ão está a ver como se chegou aqui? Eu explico novamente. E com toda a simpatia e boa vontade repetia a exposição. Era impressionante como ele em uma sala cheia conseguia detectar pelas expressões dos rostos aqueles que não estavam compreendendo o raciocínio. M aria $M$ anuela lembra que quando as aulas acabavam havia sempre muitos alunos que ficavam na sala, à volta do Professor Caraça a tirar dúvidas ou a falar com ele sobre outros assuntos e que o professor Caraça estava sempre pronto a indicar pistas e que nunca faltava a nenhuma palestra dos estudantes, sentado na primeira fila, ouvindo com toda a atenção e, no fim, chamando o estudante, homem ou mulher, para a elogiar ou fazer a sua crítica.

\section{Conclusões}

Por todo o exposto, depreende-se a enorme importância de resgatar os dados da vida e da obra de Bento de Jesus C araça, suas opiniões e os seus exemplos de luta em prol da dignidade e da felicidade humana. Acima do valor de suas posições educacionais, de sua visão histórico-dialética da produção do conhecimento, de sua interpretação do desenvolvimento da $M$ atemática, paira soberana uma lição de coerência e dignidade que foi a sua própria vida enquanto homem e educador matemático de relevo. A principal lição que Caraça nos deixa é, portanto, a da coerência entre as palavras e as atitudes, sentimento este que exprimiu tão bem em suas próprias palavras ao afirmar, como no tom de uma missão a ser seguida: Precisamos, para não trair a nossa missão, de nos forjarmos personalidades íntegras, de analisarmos o nosso tempo e de atuar como homens dele (1978, p. 48).

\section{Referências}

ABREU, A. Bento de Jesus Caraça: notas biográficas. A Cultura Integral do Indivíduo. Lisboa: Pelouro da Educação da Câmara M unicipal de Lisboa, 1995.

ALEN CAR, F. H istória da sociedade brasileira: 20 grau. 2. ed. Rio de Janeiro: Ao Livro Téenico, 1985.

ALT H U SSER, L. I deologia e aparelhos ideológi cos de Estado. 3. ed. Lisboa: Editorial Presença/M artins Fontes, 1980. 
BARATA-M O U RA, J. Linhas de rumo do pensamento de Bento de Jesus Caraça. Lisboa: Instituto Superior de Economia e G estão - ISEG, 2001.

BASTO , L. N essas reuniões na brasileira Bento $C$ araça fazia verdadeiros cursos no café. In: BEN TO Jesus C araça: Perspectivas sobre o homem e a obra. Guarda: Instituto Politécnico da Guarda, 2001.

BEBIAN O, N . Bento de Jesus C araça e a M atemática, aquela difusa substância. Gazeta de M atemática, Lisboa, n.141, p. 11-23, Jul. 2001.

Bento de Jesus C araça: esboço biográfico. Gazeta de M atemática, Lisboa, n.141, p. 9-10, Jul. 2001.

BELO, E. Além do professor nós víamos o cidadão interveniente. In: Bento Jesus Caraça: perspectivas sobre o homem e a obra. Guarda: Instituto Politécnico da Guarda, 2001. Bento Jesus C araça: perspectivas sobre o homem e a obra. Guarda: Instituto Politécnico de Guarda, 2001.

CARAÇA, B. J. C arta a M anuel Amado da Cunha, 16/01/1943. In: VILAÇA, Alberto. Bento de Jesus Caraça: militante integral do ser humano. Porto: Campo das Letras, 1999. p. 243-245.

. A Cultura integral do indivíduo. Lisboa: Câmara M unicipal, 1995.

. A Cultura integral do indivíduo: problema central do nosso tempo. In: J.M.C.

(Ed). Bento de Jesus C araça: conferências e outros escritos. Lisboa: Tipografia Antonio Coelho Dias, 1978.

Algumas reflexões sobre a Arte. In: J.M .C. (Ed). Bento de Jesus Caraça: conferências e outros escritos. Lisboa: Tipografia Antonio Coelho Dias, 1978.

. As U niversidades populares e a cultura In: J.M .C. (Ed). Bento de Jesus Caraça: conferências e outros escritos. Lisboa: Tipografia Antonio Coelho Dias, 1978.

. Rabindranath Tagore . In: J.M .C. (Ed). Bento de Jesus Caraça: conferências e outros escritos. Lisboa: Tipografia Antonio Coelho Dias, 1978.

. A M atemática na vida dos homens In: J.M .C. (Ed). Bento de Jesus Caraça: conferências e outros escritos. Lisboa: Tipografia Antonio Coelho Dias, 1978.

. Escola única. In: J.M .C. (Ed). Bento de Jesus Caraça: conferências e outros escritos. Lisboa: Tipografia Antonio Coelho Dias, 1978.

. H umanismo e humanidades. In: J.M .C. (Ed). Bento de Jesus C araça: conferências e outros escritos. Lisboa: Tipografia Antonio Coelho Dias, 1978.

. Concei tos fundamentais da M atemática. Lisboa: G ráfica Brás M onteiro Ltda, 1975. CARAÇA, J. Bento de Jesus C araça: Cem Anos pela Fraternidade. Gazeta de M atemática, Lisboa, n. 141, p. 5-6, Jul. 2001.

COELH O, A. Bento de Jesus Caraça. Sessão Pública em Vila Viçosa. 21 de Abril de 2001.

. Bento de Jesus C araça: Um H omem Espantoso e Admirável. Trabalho e Sociedade: Ciclo de Conferências In: Bento Jesus Caraça: perspectivas sobre o homem e a obra. Guarda: Instituto Politécnico de Guarda, 2001.

CUN H AL, A. Bento C araça: insigne intelectual comunista. Entrevista. Jornal Avante, n. 1431, p. 1, M aio 2001. 
DIN IS, L. U ma Carta de Bento C araça para o meu pai. In: Bento Jesus Caraça: perspectivas sobre o homem e a obra. Guarda: Instituto Politécnico de Guarda, 2001.

D O BREIRA, C. Bento de Jesus C araça, cidadão e amante da Serra da Estrela -

D epoimento. In: Bento Jesus Caraça: perspectivas sobre o homem e a obra. Guarda: Instituto Politécnico de Guarda, 2001.

D O RES, A. O Papel da universidade popular portuguesa ao serviço da cultura do povo.

Boletim 0 Erro, Escola Profissional Bento de Jesus Caraça, n.1, Abr. 2001.

FISH ER, M. As M inhas recordações das lições do professor Bento de Jesus Caraça e da sua personalidade. In: Bento Jesus C araça: perspectivas sobre o homem e a obra. Guarda: Instituto Politécnico de Guarda, 2001.

FUN D AÇÃO M ARIO SO ARES. 100ำ Aniversário do N ascimento de Bento Jesus C araça: 18 de abril de 2001. Disponível em: 〈http://www.fmsoares.pt/novidades/bjc-grande.htm> Acesso em: 6 set. 2001.

GUSM ÃO , M. Bento de Jesus C araça: 1901-2001. In: Bento Jesus Caraça: perspectivas sobre o homem e a obra. Guarda: Instituto Politécnico de Guarda, 2001.

J.M .C. (Ed) Bento de Jesus Caraça: conferências e outros escritos 2. ed. Lisboa: Tipografia Antonio C oelho Dias Ltda., 1978.

GRAM SCI, A. O sIntelectuais e a organização da cultura 4. ed. Rio de Janeiro: Civilização Brasileira, 1982.

LAM I, G. "Ah, não gosta de M atemática, então vai passar a gostar". In: BEN TO Jesus

C araça: perspectivas sobre o homem e a obra. Guarda: Instituto Politécnico de Guarda, 2001. . Conceitos fundamentais da M atemática: al gumas reflexões sobre o seu conteúdo e alcance pedagógico. In: Bento Jesus Caraça: perspectivas sobre o homem e a obra. Guarda: Instituto Politécnico de Guarda, 2001.

M ELO, L. M emórias do século. Notícias M agazine, n. 76, 2001.

N ASCIM EN TO, U. Bento de Jesus C araça: o homem e o seu tempo. Gazeta de M atemática, Lisboa, n.141, p. 7-8, Jul. 2001.

RIBEIRO, S. Seminário de M atemáticas G erais Bento de Jesus Caraça: testemunho. In: Bento Jesus Caraça: perspectivas sobre o homem e a obra. Guarda: Instituto Politécnico de Guarda, 2001.

SU CEN A, P. Bento Caraça: relance sobre o seu percurso humano e cívico. D isponível em: বttp://www.cgtp.pt/bjc100/sessam/sucena.htm>Acessado em: 14 nov. 2001.

VILAÇA, A. Bento de Jesus Caraça: militante integral do ser integral. Porto: Campo das Letras, 1999.

\section{Artigo recebido em abril de 2003 e selecionado para publicação em setembro de 2003.}

